\title{
Density Functional Theoretical Study on the C-H Coupling Reaction from Ir(III) Complexes
}

\author{
Hyun Cho, Yong-Jae Lee, ${ }^{\dagger}$ Han Young Woo, ${ }^{\ddagger}$ and Sungu Hwang ${ }^{\S, *}$ \\ Department of Nanosystem and Nanoprocess Engineering, Pusan National University, Miryang 627-706, Korea \\ ${ }^{\dagger}$ Department of Horticultural Bioscience, Pusan National University, Miryang 627-706, Korea \\ ${ }^{\ddagger}$ Department of Cogno-Mechatronics Engineering, Pusan National University, Miryang 627-706, Korea \\ ${ }^{\S}$ Department of Nanomedical Engineering, Pusan National University, Miryang 627-706, Korea \\ *E-mail: sungu@pusan.ac.kr
}

Received December 31, 2009, Accepted January 13, 2010

Key Words: DFT, Reductive elimination, Ir(III), Pincer ligand

The $\mathrm{C}-\mathrm{H}$ bond activation reaction, which was catalyzed by metal complexes, has been the subject of intensive studies because of its relevance to the selective oxidation of methane and higher alkanes. ${ }^{1}$ Ir catalysts supported by pincer ligands have been one of the most widely studied systems. Recently, the competitive $\mathrm{C}_{\mathrm{Ph}}-\mathrm{H}$ and $\mathrm{C}_{\mathrm{Me}}-\mathrm{H}$ carbon-hydrogen coupling reactions have been reported for the $\operatorname{Ir}$ (III) complexes. Ir complexes were synthesized with the tridentate pincer ligand of 2,6-bis(ditert-butylphosphinito)pyridine (PONOP) $\left(\mathbf{1}^{+}\right.$and $\mathbf{2}^{+}$shown in Scheme 1), and the kinetic studies were performed for the C-H

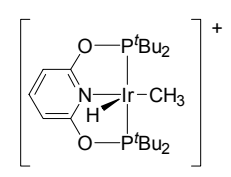

$1^{+}$

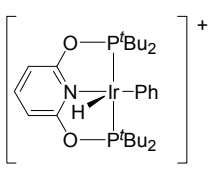

$\mathbf{2}^{+}$
Scheme 1

$$
\Delta G_{298 \mathrm{~K}, \mathrm{CHCl}_{3}}\left(\Delta G_{298 \mathrm{~K}, \text { gas }}\right)
$$

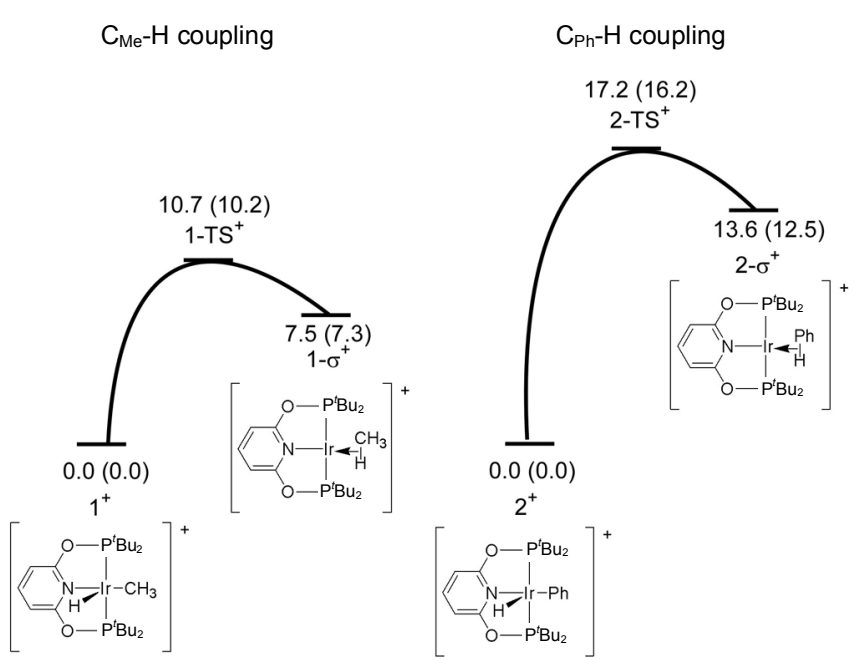

Figure 1. Relative Gibbs free energy diagram from the B3LYP/ LACVP** calculations, where TS denotes the transition state, and $\sigma$ denotes the $\sigma$-complex (The values in parentheses are the gas-phase data). bond coupling from these five-coordinate complexes. ${ }^{2}$ The activation energy barrier of the $\mathrm{C}_{\mathrm{Ph}}-\mathrm{H}$ coupling was higher than the $\mathrm{C}_{\mathrm{Me}}-\mathrm{H}$ coupling, which was not expected from the earlier theoretical works and usual speculation: ${ }^{3,4}$ Generally, the coupling rate was explained based on the orbital directionality, where the increased $s$-character in $\mathrm{sp}^{2}$ hybridization made the $\mathrm{C}-\mathrm{H}$ bond formation easier than for $\mathrm{sp}^{3}$ hybridization.

In this study, density functional theoretical (DFT) studies were conducted in order to determine the mechanism of the two coupling reactions from $\mathbf{1}^{+}$and $\mathbf{2}^{+}$. Figure 1 shows the Gibbs

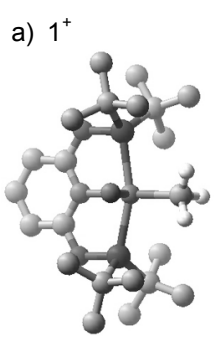

c) $1-\mathrm{TS}^{+}$

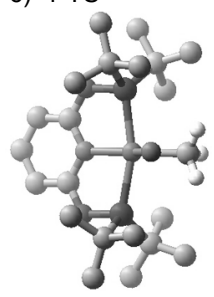

e) $1-\sigma^{+}$

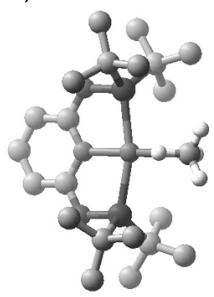

b) $2^{+}$

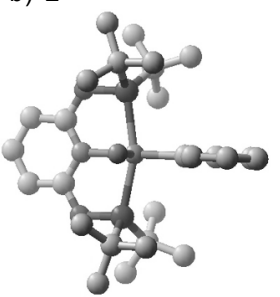

d) $2-\mathrm{TS}^{+}$

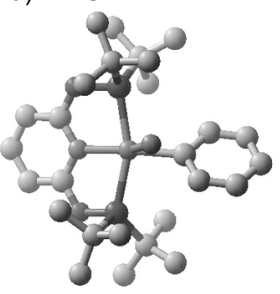

e) $2-\sigma^{+}$

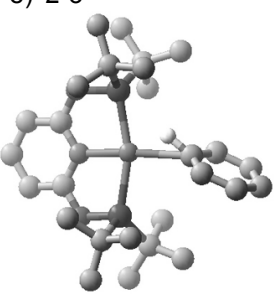

Figure 2. Optimized structures of the minima and the transition states from the B3LYP/LACVP** calculations. Except the methyl hydrogens and hydride attached to Ir, the hydrogen atoms are not shown for clarity. 
free energy diagram for intermediate $\mathbf{1}^{+}$( + denotes the fivecoordinated cationic species), and Figure 2 shows the optimized structures that were obtained from the B3LYP/LACVP** calculations. The gas-phase thermodynamic quantities were also included for comparison purposes. The Gibbs activation energy $\Delta G^{\ddagger}$ was $10.2 \mathrm{kcal} / \mathrm{mol}$ for the $\mathrm{C}_{\mathrm{Me}}-\mathrm{H}$ coupling and 16.2 $\mathrm{kcal} / \mathrm{mol}$ for the $\mathrm{C}_{\mathrm{Ph}}-\mathrm{H}$ coupling in the gas phase at $298 \mathrm{~K}$. Both of these values were in good agreement with the NMR experimental results of $\Delta G^{\ddagger}=9.3 \mathrm{kcal} / \mathrm{mol}$ for the $\mathrm{C}_{\mathrm{Me}}-\mathrm{H}$ coupling and $\Delta G^{\ddagger}=17.8 \mathrm{kcal} / \mathrm{mol}$ for the $\mathrm{C}_{\mathrm{Ph}}-\mathrm{H}$ coupling. The solvation energy correction marginally changed the numerical results, with values of $\Delta G^{\ddagger}=10.7 \mathrm{kcal} / \mathrm{mol}$ for the $\mathrm{C}_{\mathrm{Me}}-\mathrm{H}$ coupling and $\Delta G^{\ddagger}=17.2 \mathrm{kcal} / \mathrm{mol}$ for the $\mathrm{C}_{\mathrm{Ph}}-\mathrm{H}$ coupling.

The geometries of the reactants, the transition states, and the $\sigma$-complexes were examined in order to understand the higher energy barrier of the $\mathrm{H}-\mathrm{C}_{\mathrm{Ph}}$ coupling compared to the $\mathrm{H}-\mathrm{C}_{\mathrm{Me}}$ coupling. Figure 2 shows the optimized structures from the $\mathrm{B} 3 \mathrm{LYP} / \mathrm{LACVP} * *$ calculations.

In Figure 2, the Ir complexes $\mathbf{1}^{+}$and $\mathbf{2}^{+}$exhibited square pyramidal geometries with a nearly planar coordination environment that was centered around Ir. The Ir- $\mathrm{C}_{\mathrm{Me}}$ bond length in $\mathbf{1}^{+}$ was $2.10 \AA$, which was comparable to the value that was found in the X-ray structure ${ }^{2}$ and the related pincer Ir(III)-methyl complexes. ${ }^{5}$ The Ir- $\mathrm{C}_{\mathrm{Ph}}$ bond length in $\mathbf{2}^{+}$was $2.07 \AA$, which was also comparable to the value that was found in the related pincer Ir(III)-phenyl complexes. ${ }^{5}$ The phenyl ring in $2^{+}$was vertical to the plane that was defined by Ir and its pincer ligand, and therefore, the hydrogen atom that was attached to Ir was also in the same plane. The Ir-H bond lengths were $1.54 \AA$ in $\mathbf{1}^{+}$and $1.53 \AA$ in $2^{+}$.

In $1-\mathbf{T S}^{+}$, the Ir-H bond length was elongated to $1.60 \AA$, the Ir- $\mathrm{C}_{\mathrm{Me}}$ bond was stretched to $2.24 \AA$, resulting in a $\mathrm{H}-\mathrm{C}_{\mathrm{Me}}$ distance of $1.48 \AA$ and a $\mathrm{H}-\mathrm{Ir}-\mathrm{C}_{\mathrm{Me}}$ angle of $41.3^{\circ}$, compared to $90.4^{\circ}$ in $\mathbf{1}^{+}$. In $\mathbf{2 - \mathbf { T S } ^ { + }}$, the Ir-H bond length was elongated to $1.61 \AA$, and the $\mathrm{Ir}-\mathrm{C}_{\mathrm{Ph}}$ bond was $2.16 \AA$, resulting in a $\mathrm{H}-\mathrm{C}_{\mathrm{Ph}}$ distance of $1.48 \AA$ and a H-Ir- $\mathrm{C}_{\mathrm{Ph}}$ angle of $43.2^{\circ}$ compared to $89.1^{\circ}$ in $\mathbf{2}^{+}$. The phenyl ring rotated $\sim 53^{\circ}$ with respect to the $\mathrm{Ir}-\mathrm{C}_{\mathrm{Ph}}$ axis, compared to its position in $2^{+}$. However, a corresponding rota-

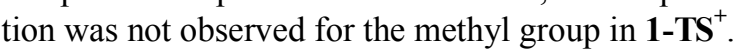

In $1-\sigma^{+}$, the Ir-H bond length was elongated to $1.83 \AA$, and the Ir- $\mathrm{C}_{\mathrm{Me}}$ bond was lengthened to $1.48 \AA$. On the other hand, the $\mathrm{H}-\mathrm{C}_{\mathrm{Me}}$ distance was shortened to $1.16 \AA$. In $\mathbf{2}-\boldsymbol{\sigma}^{+}$, the Ir-H bond length was elongated to $1.86 \AA$, and the $\mathrm{Ir}-\mathrm{C}_{\mathrm{Ph}}$ was stretched to $2.48 \AA$. However, the $\mathrm{H}-\mathrm{C}_{\mathrm{Ph}}$ distance was shortened to $1.14 \AA$. In $2-\boldsymbol{\sigma}^{+}$, phenyl ring was vertical to the plane that was made by Ir and the pincer ring.

The most plausible path for the formation of the new $\mathrm{H}-\mathrm{C}_{\mathrm{Ph}}$ bond was that the hydrogen atom that was located above the phenyl ring and made a "face-on" approach to the phenyl ring as long as the geometry was not constrained. However, the bulky $t$-butyl groups that were attached to the phosphorus atoms in $\mathbf{2}^{+}$caused a constraint on the vertical location of hydrogen with respect to the phenyl ring in $\mathbf{2}^{+}$, which created a very large steric barrier to the rotation of the phenyl ring that was attached to the Ir atom during the transition from $\mathbf{2}^{+}$to 2 - $\mathbf{T S}^{+}$.

Additional calculations were performed in order to confirm this hypothesis. The $t$-butyl groups that were attached at the phosphorus atom were replaced with methyl groups in order to

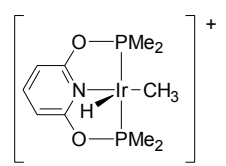

$3^{+}$

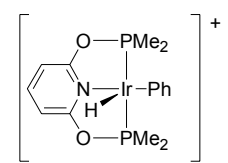

$4^{+}$
Scheme 2

study the steric effect (See Scheme 2). The Gibbs activation energy was reduced to $8.4 \mathrm{kcal} / \mathrm{mol}$ for the $\mathrm{C}_{\mathrm{Me}}-\mathrm{H}$ coupling in $3^{+}$and $8.7 \mathrm{kcal} / \mathrm{mol}$ for the $\mathrm{C}_{\mathrm{Ph}}-\mathrm{H}$ coupling in $\mathbf{4}^{+}$in the gas phase. The solvation energy correction adjusted the $\Delta G^{\ddagger}$ values to 9.6 $\mathrm{kcal} / \mathrm{mol}$ for the $\mathrm{C}_{\mathrm{Me}}-\mathrm{H}$ coupling and $9.8 \mathrm{kcal} / \mathrm{mol}$ for the $\mathrm{C}_{\mathrm{Ph}}-\mathrm{H}$ coupling. As expected from the structural analysis for $\mathbf{1}^{+}$and $2^{+}$, the Gibbs activation energy for the $\mathrm{C}_{\mathrm{Ph}}-\mathrm{H}$ coupling was significantly reduced because the methyl group in $\mathbf{4}^{+}$was smaller than the $t$-butyl group in $2^{+}$. The change in $\Delta G^{*}$ was much smaller for the $\mathrm{C}_{\mathrm{Me}}-\mathrm{H}$ coupling than the $\mathrm{C}_{\mathrm{Ph}}-\mathrm{H}$ coupling because of the smaller steric hindrance. Therefore, the activation energies of the $\mathrm{C}_{\mathrm{Me}}-\mathrm{H}$ coupling and the $\mathrm{C}_{\mathrm{Ph}}-\mathrm{H}$ coupling were comparable to each other when methyl groups were attached to the phosphorus atoms. These results were consistent with the previous computational results ${ }^{6}$ and the experimental observations ${ }^{7}$ for the Pt pincer type complexes.

In summary, the DFT calculations were performed on the C-H coupling reaction for the pincer type Ir (III) complexes. The transition states were successfully located, and the thermodynamic and kinetic results were consistent with the existing experimental data ${ }^{2}$ and previous computational results ${ }^{6}$ for the same type of complexes. The bulky $t$-butyl groups that were attached to the phosphorous atoms caused geometric constraint and steric hindrance to the phenyl rotation.

\section{Computational Details}

The geometry was optimized at the B3LYP/LACVP** level of the theory using the Jaguar v5.5 suite. ${ }^{8}$ The stability of all of the minima, including the intermediates and the transition states (TSs), was evaluated by calculating the standard Gibbs energy of each species at $298.15 \mathrm{~K}$. The standard Gibbs energy of a molecule was evaluated using the following equation.

$$
\Delta G=E_{0}+\mathrm{ZPE}+\Delta \Delta G_{0 \rightarrow 298} .
$$

The total energy of the molecule at $0 \mathrm{~K}\left(E_{0}\right)$ was calculated at the optimal geometry from the B3LYP/LACVP** level of the computations. The zero-point energy (ZPE) and the Gibbs free energy change from $0 \mathrm{~K}$ to $298.15 \mathrm{~K}\left(\Delta \Delta G_{0 \rightarrow 298}\right)$ were evaluated at the same level of the theory. The thermodynamic quantities were evaluated according to the rigid-rotor harmonic oscillator approximation using the computed harmonic frequencies from the B3LYP/LACVP** calculations. The local minima and the TSs were identified using the analysis of the harmonic frequencies from the analytical Hessian calculations. The reaction paths were traced from the TSs using the intrinsic reaction coordinate (IRC) method ${ }^{9,10}$ in order to confirm if the reactants and products were correct. The Poison-Boltzmann (PB) continuum model ${ }^{11,12}$ was used in order to describe the sol- 
vent $\left(\mathrm{CHCl}_{3}\right)$ at the B3LYP/LACVP** level with a solvent probe radius of $2.52 \AA$ and a solvent dielectric constant of $4.8 .{ }^{13}$ The solvation energy corrections were calculated for the optimized gas phase geometries at the B3LYP/LACVP** level.

Acknowledgments. This work was supported by a Pusan National University Research Grant.

\section{References}

1. Ess, D. H.; Nielsen, R. J.; Goddard III, W. A.; Periana, R. A. J. Am. Chem. Soc. 2009, 131, 11686.

2. Bernskoetter, W. H.; Hanson, S. K.; Buzak, S. K.; Davis, Z.; White, P. S.; Swartz, R.; Goldberg, K. I.; Brookhart, M. J. Am. Chem. Soc. 2009, 131, 8603 .

3. Low, J. J.; Goddard III, W. A. J. Am. Chem. Soc. 1984, 106, 8321.

4. Low, J. J.; Goddard III, W. A. Organometallics 1986, 5, 609.
5. Ghosh, R.; Emge, T. J.; Krogh-Jespersen, K.; Goldman, A. S. J. Am. Chem. Soc. 2008, 130, 11317.

6. Hwang, S.; Woo, H. Y.; Cho, H.; Jang, J. Bull. Korean Chem. Soc. 2008, 29, 537.

7. Madison, B. L.; Thyme, S. B.; Keene, S.; Williams, B. S. J. Am. Chem. Soc. 2007, 129, 9538.

8. Jaguar v5.5; Schrodinger Inc.: Portland, Oregon, 2003.

9. Gonzalez, C.; Schlegel, H. B. J. Chem. Phys. 1989, 90, 2154.

10. Gonzalez, C.; Schlegel, H. B. J. Phys. Chem. 1990, 94, 5523.

11. Marten, B.; Kim, K.; Cortis, C.; Friesner, R. A.; Murphy, R. B.; Ringnalda, M. N.; Sitkoff, D.; Honig, B. J. Phys. Chem. 1996, 100, 11775.

12. Tannor, D. J.; Marten, B.; Murphy, R.; Friesner, R. A.; Sitkoff, D.; Nicholls, A.; Ringnalda, M. N.; Goddard III, W. A.; Honig, B. J. Am. Chem. Soc. 1994, 116, 11875.

13. Kent IV, D. R.; Dey, N.; Davidson, F.; Gragoire, F.; Petterson, K. A.; Goddard III, W. A.; Roberts, J. D. J. Am. Chem. Soc. 2002, $124,9318$. 